\title{
Obesity attenuates gender differences in cardiovascular mortality
}

\author{
Xin Song ${ }^{1,2 *}$, Adam G Tabák ${ }^{3,4}$, Björn Zethelius ${ }^{5,6}$, John S Yudkin , Stefan Söderberg ${ }^{8,9}$, Tiina Laatikainen 2,10,11, \\ Coen DA Stehouwer ${ }^{12}$, Rachel Dankner ${ }^{13,14}$, Pekka Jousilahti ${ }^{2}$, Altan Onat ${ }^{15}$, Peter M Nilsson ${ }^{16,17}$, Ilhan Satman ${ }^{18}$, \\ Olga Vaccaro ${ }^{19}$, Jaakko Tuomilehto 2,20,21,22 and Qing Qiao ${ }^{1,2,23}$ for the DECODE Study Group
}

\begin{abstract}
Background: To estimate cardiovascular disease (CVD) mortality in relation to obesity and gender.

Methods: Data from 11 prospective cohorts from four European countries including 23629 men and 21965 women, aged 24 to 99 years, with a median follow-up of 7.9 years were analyzed. Hazards ratios (HR) for CVD mortality in relation to baseline body mass index (BMI), waist circumference (WC), waist-to-hip ratio (WHR) and waist-to-height ratio (WHtR) were estimated using Cox proportional hazards models with age as the timescale.

Results: Men had higher CVD mortality than women in all four BMl categories (<25.0, 25.0-29.9, 30.0-34.9 and $\left.\geq 35.0 \mathrm{~kg} / \mathrm{m}^{2}\right)$. Compared with the lowest BMI category in women, multivariable adjusted HRs ( $95 \%$ confidence intervals) for higher BMl categories are 1.0 (0.8-1.4), 1.6 (1.1-2.1) and 2.8 (2.0-3.8) in women and 2.8 (2.2-3.6), 3.1 (2.5-3.9), 3.8 (2.9-4.9) and 5.4 (3.8-7.7) in men, respectively. Similar findings were observed for abdominal obesity defined by WC, WHR or WHtR. The gender difference was slightly smaller in obese than in non-obese individuals; but the interaction was statistically significant only between gender and WC $(p=0.02)$, and WHtR $(p=0.01)$. None of the interaction terms was significant among non-diabetic individuals.
\end{abstract}

Conclusions: Men had higher CVD mortality than women across categories of anthropometric measures of obesity. The gender difference was attenuated in obese individuals, which warrants further investigation.

Keywords: Obesity, Gender, Cardiovascular disease mortality

\section{Background}

Cardiovascular diseases (CVD) are still the leading cause of mortality in both men and women [1]. Further, women are known to have a much lower risk for CVD mortality than men. There is substantial evidence of a gender difference in cardiac autonomic modulation [2-5], lipid and glucose metabolism [6-9], sex hormones [4,10-14] and cytokines [15-19]. On average, women would have augmented sympathetic inhibition, higher cardiac vagal tone, higher heart rate variability, lower susceptibility to arrhythmias, and decreased myocardial contractility than men $[2,3,20]$, leading to a preponderance of vagal over sympathetic control of cardiac function [2-5]. Moreover,

\footnotetext{
*Correspondence: xin.song@helsinki.fi

'Department of Public Health, Hjelt Institute, University of Helsinki, Helsinki, Finland

2Department of Chronic Disease Prevention, National Institute for Health and Welfare, Helsinki, Finland

Full list of author information is available at the end of the article
}

before menopause, women generally have lower levels of serum total and low-density lipoprotein cholesterol (TC and LDL-C), triglycerides and apolipoprotein $\mathrm{B}$ and higher levels of high-density lipoprotein cholesterol (HDL-C) and apolipoprotein A-I than their male counterparts [6,21-23] although TC and LDL-C increase in women after menopause [21,22]. However, this female advantage is abrogated with diabetes and aging [24-32], perhaps as a consequence of diabetes inducing higher levels of inflammatory markers and higher rates of nitric oxide release in women compared with men, resulting in reduced protective effects of estrogen on body fat distribution and insulin action, or a more impaired endothelial function in women than in men $[10,33]$. The prevalence of obesity is rising worldwide, leading to an increased risk for diabetes and CVD $[34,35]$. It is not clear, however, whether the gender 
difference in CVD mortality remains after accounting for the increased development of obesity.

The aim of this study was to assess the risk of CVD mortality in relation to obesity and gender [1] in the general population and [2] separately for those with or without diabetes at baseline.

\section{Subjects and methods Study population}

This analysis was based on 11 cohorts from the DECODE (Diabetes Epidemiology: Collaborative analysis Of Diagnostic criteria in Europe) study including 45594 individuals (48.2\% women) aged $24-99$ at baseline, from four European countries (Finland, Sweden, Turkey and UK). Information on weight, height, waist and hip circumferences, self-reported smoking status, leisure-time physical activity, and history of diabetes mellitus were available. In addition, 20270 individuals (44.7\% women) had data on fasting or 2-h plasma glucose (FPG and 2hPG) from a $75 \mathrm{~g}$ oral glucose tolerance test. Individual participant data from each cohort were sent to the National Institute for Health and Welfare in Helsinki, Finland for collaborative data analyses. Studies included were approved by local ethics committees, and the analysis plan was approved by the ethics committee of the National Institute for Health and Welfare, Helsinki, Finland.

\section{Definition of covariates}

Height and weight were measured without shoes and with light clothing. Waist circumference (WC) was measured midway between the lower rib margin and iliac crest. Hip circumference was measured at the level of the widest circumference over the greater trochanters. Body mass index (BMI) was calculated as weight in kilograms divided by the square of height in meters. Waist-to-hip ratio (WHR) and waist-to-height ratio (WHtR) were calculated as waist circumference divided by hip circumference or height, respectively. Participants were classified into five categories: underweight (BMI $<18.5 \mathrm{~kg} / \mathrm{m}^{2}$ ), normal weight (BMI 18.5-24.9 kg/m²), overweight (BMI 25.0-29.9 kg/ $\mathrm{m}^{2}$ ), obesity (BMI $30.0-34.9 \mathrm{~kg} / \mathrm{m}^{2}$ ) and severe obesity (BMI $\geq 35.0 \mathrm{~kg} / \mathrm{m}^{2}$ ), according to the WHO classification criteria [36]. Due to the low number of participants in the underweight category in this study population, the underweight and normal weight groups were combined for analysis. Abdominal obesity was defined as the sex-specific top quartile of WC, WHR or WHtR (WC $\geq 99 \mathrm{~cm}, \mathrm{WHR} \geq 0.97$, and WHtR $\geq 0.57$ for males; WC $\geq 90 \mathrm{~cm}$, WHR $\geq 0.85$, and WHtR $\geq 0.56$ for females, respectively). Participants reporting reading, watching TV, housework, sewing and walking $<1 \mathrm{~km}$ daily were defined as physically inactive; all those engaging in higher levels of physical activity were defined as physically active. Based on responses to the questionnaire, smoking status at baseline was classified into three categories of never, former and current smokers. Diabetes was defined as either a history of diabetes at baseline or an FPG level $\geq 7.0 \mathrm{mmol} / \mathrm{L}$ and/or a $2 \mathrm{hPG}$ level $\geq 11.1 \mathrm{mmol} / \mathrm{L}$ [37].

\section{Definition of fatal events}

Vital status and causes of death were recorded for all participants. CVD mortality was defined according to the International Classification of Disease codes 401-448 (9th revision) or I10-I79 (10th revision).

\section{Statistical analyses}

The absolute CVD mortality rate per 10000 person-years of follow-up for each obesity and gender category was calculated. Cox proportional hazards models were used to estimate hazard ratios (HR) and 95\% confidence intervals (CIs) for CVD mortality, adjusting for baseline smoking status, leisure-time physical activity and cohort, using attained age as the timescale and non-obese women as the reference group. To investigate whether the gender difference in CVD mortality was different in non-obese from obese participants, we checked for the interaction between sex and obesity in the Cox models, using a chi-squared log-likelihood ratio test. STATA version 11 (StataCorp, College Station, TX, USA) was used.

\section{Results}

Table 1 provides baseline characteristics of the cohorts. Median follow-up time varied between 2.5 and 21.8 years in the different cohorts. Lean females were younger, more abdominally obese and had low prevalence of diabetes, while obese females were older, less abdominally obese and had higher prevalence of diabetes at baseline, compared with their respective male counterparts (Table 2). More men than women were smokers and physically active. Men tended to have higher mean values of systolic blood pressure and fasting plasma glucose, and a worse lipid profile than women, regardless of BMI categories. Similar characteristics were observed among non-diabetic individuals (Additional file 1: Table S1). But diabetic men tended to be older and less physically active. Similar gender specific baseline characteristics were observed within the categories of abdominal obesity defined by sex-specific quartiles of anthropometric measures of WC, WHR and WHtR (Additional file 1: Table S2).

During the median follow-up of 7.9 years, 945 (4.0\%) men and 339 (1.5\%) women died from CVD. Absolute rates and age- or multivariate-adjusted HRs for CVD mortality are shown across BMI categories or sex-specific quartiles of anthropometric measures of abdominal obesity (Table 3). Males had higher CVD mortality rates and higher hazard ratios across BMI categories, and categories 
Table 1 Baseline characteristics and follow-up information of the survey participants

\begin{tabular}{|c|c|c|c|c|c|c|c|c|}
\hline Study & $\begin{array}{l}\text { Number of } \\
\text { participants }\end{array}$ & $\begin{array}{l}\text { Age } \\
\text { (years) }\end{array}$ & BMI $\left(\mathrm{kg} / \mathrm{m}^{2}\right)$ & WC $(\mathrm{cm})$ & WHR & WHtR & $\begin{array}{l}\text { Median } \\
\text { follow-up } \\
\text { (years) }\end{array}$ & $\begin{array}{l}\text { No. }(\%) \text { of } \\
\text { CVD deaths }\end{array}$ \\
\hline \multicolumn{9}{|l|}{ Men } \\
\hline \multicolumn{9}{|l|}{ Finland } \\
\hline FINRISK (1987) & 2541 & $43.8(11.2)$ & $26.7(3.7)$ & $92.2(10.7)$ & $0.90(0.06)$ & $0.53(0.06)$ & 21.8 & $293(11.5)$ \\
\hline FINRISK (1992) & 2570 & $44.3(11.2)$ & $26.6(3.9)$ & $93.9(11.2)$ & $0.92(0.07)$ & $0.53(0.07)$ & 16.8 & $152(5.9)$ \\
\hline FINRISK (1997) & 3788 & $48.6(13.5)$ & $26.9(3.9)$ & $94.5(11.3)$ & $0.93(0.07)$ & $0.54(0.07)$ & 11.8 & $205(5.4)$ \\
\hline FINRISK (2002) & 3808 & $48.0(13.0)$ & $27.2(4.1)$ & $95.4(11.8)$ & $0.97(0.07)$ & $0.54(0.07)$ & 6.8 & $69(1.8)$ \\
\hline \multicolumn{9}{|l|}{ Sweden } \\
\hline Northern Sweden MONICA (1986) & 671 & $46.0(11.4)$ & $25.4(3.4)$ & $92.4(9.2)$ & $0.94(0.05)$ & $0.52(0.06)$ & 20.5 & $49(7.3)$ \\
\hline Northern Sweden MONICA (1990) & 761 & $45.0(11.3)$ & $25.8(3.3)$ & $91.4(9.1)$ & $0.93(0.06)$ & $0.52(0.05)$ & 16.5 & $30(3.9)$ \\
\hline Northern Sweden MONICA (1994) & 877 & $49.6(14.0)$ & $26.2(3.7)$ & $93.4(10.1)$ & $0.94(0.06)$ & $0.53(0.06)$ & 12.5 & $37(4.2)$ \\
\hline Northern Sweden MONICA (1999) & 869 & $50.6(14.3)$ & $26.7(3.5)$ & $95.3(9.7)$ & $0.92(0.07)$ & $0.54(0.06)$ & 7.4 & $14(1.6)$ \\
\hline Northern Sweden MONICA (2004) & 864 & $50.9(14.1)$ & $27.2(3.9)$ & $96.4(10.7)$ & $0.96(0.06)$ & $0.54(0.06)$ & 2.5 & 0 \\
\hline \multicolumn{9}{|l|}{ Turkey } \\
\hline TARFS (1998-2002) & 1580 & $53.2(12.4)$ & $26.4(4.0)$ & $94.3(11.0)$ & $0.93(0.07)$ & $0.56(0.06)$ & 7.9 & $55(3.5)$ \\
\hline \multicolumn{9}{|l|}{ UK } \\
\hline Whitehall II (1991-1993) & 5300 & $49.3(6.0)$ & $25.1(3.2)$ & $87.4(9.2)$ & $0.90(0.06)$ & $0.50(0.05)$ & 5.9 & $41(0.8)$ \\
\hline Total & 23629 & $48.0(11.8)$ & $26.4(3.8)$ & $92.6(11.0)$ & $0.93(0.07)$ & $0.53(0.07)$ & 7.9 & $945(4.0)$ \\
\hline \multicolumn{9}{|l|}{ Women } \\
\hline \multicolumn{9}{|l|}{ Finland } \\
\hline FINRISK (1987) & 2812 & $43.7(11.4)$ & $26.0(4.9)$ & $79.4(11.2)$ & $0.78(0.06)$ & $0.49(0.07)$ & 21.8 & $119(4.2)$ \\
\hline FINRISK (1992) & 2828 & $44.0(11.5)$ & $25.7(4.9)$ & $80.2(11.7)$ & $0.79(0.07)$ & $0.49(0.08)$ & 16.9 & $55(1.9)$ \\
\hline FINRISK (1997) & 3788 & $46.1(12.7)$ & $26.1(4.9)$ & $81.3(12.2)$ & $0.80(0.07)$ & $0.50(0.08)$ & 11.8 & $61(1.6)$ \\
\hline FINRISK (2002) & 4383 & $46.6(13.0)$ & $26.4(5.0)$ & $83.6(12.6)$ & $0.84(0.06)$ & $0.52(0.08)$ & 6.8 & $14(0.3)$ \\
\hline \multicolumn{9}{|l|}{ Sweden } \\
\hline Northern Sweden MONICA (1986) & 685 & $45.6(11.1)$ & $25.0(4.4)$ & $85.3(12.2)$ & $0.86(0.07)$ & $0.52(0.08)$ & 20.5 & $18(2.6)$ \\
\hline Northern Sweden MONICA (1990) & 793 & $44.8(11.4)$ & $25.0(4.4)$ & $79.4(11.0)$ & $0.81(0.06)$ & $0.49(0.07)$ & 16.5 & $12(1.5)$ \\
\hline Northern Sweden MONICA (1994) & 902 & $49.4(14.0)$ & $25.8(4.7)$ & $84.2(12.4)$ & $0.83(0.08)$ & $0.52(0.08)$ & 12.5 & $16(1.8)$ \\
\hline Northern Sweden MONICA (1999) & 900 & $50.1(14.1)$ & $26.3(4.6)$ & $84.9(11.8)$ & $0.82(0.07)$ & $0.52(0.08)$ & 7.5 & $3(0.3)$ \\
\hline Northern Sweden MONICA (2004) & 909 & $49.7(13.9)$ & $26.6(5.1)$ & $86.6(12.9)$ & $0.85(0.07)$ & $0.53(0.08)$ & 2.5 & 0 \\
\hline \multicolumn{9}{|l|}{ Turkey } \\
\hline TARFS (1998-2002) & 1619 & $52.7(12.3)$ & $28.8(5.6)$ & $90.7(12.7)$ & $0.84(0.08)$ & $0.58(0.09)$ & 7.9 & $35(2.2)$ \\
\hline \multicolumn{9}{|l|}{ UK } \\
\hline Whitehall II (1991-1993) & 2346 & $50.2(6.1)$ & $25.7(4.7)$ & $75.5(11.7)$ & $0.77(0.07)$ & $0.47(0.07)$ & 5.8 & $6(0.3)$ \\
\hline Total & 21965 & $46.9(12.3)$ & $26.2(5.0)$ & $82.0(12.6)$ & $0.81(0.07)$ & $0.51(0.08)$ & 11.8 & $339(1.5)$ \\
\hline
\end{tabular}

Abbreviations: $B M I$ body mass index, WC waist circumference, WHR waist-to-hip ratio, WHtR waist-to-height ratio, CVD cardiovascular disease. Data are means (standard deviations) or as noted.

of abdominal obesity than females, but the sex difference tended to be attenuated in the obese categories. The interaction was statistically significant between gender and WC ( $p=0.02)$, and WHtR ( $p=0.01)$, but not significant with BMI and WHR (Table 3). For most studies, studyspecific HRs were within $10 \%$ of the pooled estimate, although there was heterogeneity by some studies for the
HRs of sex-ratio within BMI 25.0-29.9 kg/m² $\left(\mathrm{I}^{2}=95.5 \%\right.$, $\mathrm{P}<0.05$, Additional file 1: Table S3). However, exclusion of any study in the analysis had little overall influence on the main results (Additional file 1: Table S4). The finding persisted when the analysis was restricted to individuals without baseline diabetes, but the gender-obesity interaction was no longer significant in the non-diabetic population 
Table 2 Baseline characteristics of participants by body mass index and sex

\begin{tabular}{|c|c|c|c|c|c|c|c|c|c|c|c|c|}
\hline & \multicolumn{3}{|l|}{$<25.0 \mathrm{~kg} / \mathrm{m}^{2}$} & \multicolumn{3}{|l|}{$25.0-29.9 \mathrm{~kg} / \mathrm{m}^{2}$} & \multicolumn{3}{|c|}{$30.0-34.9 \mathrm{~kg} / \mathrm{m}^{2}$} & \multicolumn{3}{|l|}{$\geq 35.0 \mathrm{~kg} / \mathrm{m}^{2}$} \\
\hline & $M(n=9275)$ & $F(n=10519)$ & $\mathrm{P}^{*}$ & $M(n=10738)$ & $F(n=7142)$ & $\mathrm{P}^{*}$ & $M(n=3017)$ & $F(n=2962)$ & $\mathrm{P}^{*}$ & $M(n=599)$ & $F(n=1342)$ & $\mathrm{P}^{*}$ \\
\hline Age (years) & $45.6(11.8)$ & $42.9(11.7)$ & 0.00 & $49.0(11.5)$ & $49.7(11.7)$ & 0.00 & $51.3(11.3)$ & $52.3(11.5)$ & 0.00 & $50.6(11.3)$ & $52.4(11.1)$ & 0.00 \\
\hline \multicolumn{13}{|c|}{ Abdominal obesity $(\%)^{\dagger}$} \\
\hline WC & 0.6 & 1.3 & 0.00 & 26.9 & 24.2 & 0.00 & 91.4 & 79.3 & 0.00 & 99.7 & 98.1 & 0.01 \\
\hline WHR & 5.3 & 8.6 & 0.00 & 27.4 & 30.1 & 0.00 & 64.3 & 52.6 & 0.00 & 85.1 & 66.0 & 0.00 \\
\hline WHtR & 0.6 & 1.2 & 0.00 & 23.7 & 23.1 & 0.35 & 89.5 & 81.0 & 0.00 & 99.7 & 99.0 & 0.17 \\
\hline Diabetes status (\%) $)^{\ddagger}$ & & & 0.27 & & & 0.00 & & & 0.00 & & & 0.04 \\
\hline $\begin{array}{l}\text { Newly diagnosed } \\
\text { diabetes }\end{array}$ & 11.3 & 10.2 & & 13.4 & 16.0 & & 19.5 & 24.8 & & 24.4 & 32.6 & \\
\hline Known diabetes & 3.2 & 3.2 & & 6.0 & 5.4 & & 11.6 & 10.2 & & 17.2 & 15.0 & \\
\hline Smoking status (\%) & & & 0.00 & & & 0.00 & & & 0.00 & & & 0.00 \\
\hline Current smokers & 25.6 & 22.1 & & 23.7 & 17.6 & & 25.3 & 15.1 & & 25.2 & 13.5 & \\
\hline Former smokers & 27.9 & 17.3 & & 34.6 & 18.7 & & 38.7 & 18.7 & & 38.2 & 18.7 & \\
\hline Physically active (\%) & 83.1 & 78.6 & 0.00 & 80.4 & 77.7 & 0.00 & 73.3 & 70.7 & 0.03 & 61.9 & 62.1 & 0.96 \\
\hline $\mathrm{SBP}(\mathrm{mmHg})^{\S}$ & $127(17)$ & $124(18)$ & 0.00 & $135(18)$ & $133(21)$ & 0.00 & $142(19)$ & $140(21)$ & 0.00 & $147(20)$ & $145(22)$ & 0.04 \\
\hline $\mathrm{FPG}(\mathrm{mmo} / \mathrm{L})^{\S}$ & $5.3(0.9)$ & $5.2(0.8)$ & 0.00 & $5.5(1.1)$ & $5.4(1.0)$ & 0.00 & $5.9(1.5)$ & $5.7(1.3)$ & 0.00 & $6.4(2.2)$ & $5.9(1.7)$ & 0.00 \\
\hline $\mathrm{TG}(\mathrm{mmol} / \mathrm{L})^{5}$ & $1.3(0.9)$ & $1.0(0.6)$ & 0.00 & $1.8(1.2)$ & $1.4(0.8)$ & 0.00 & $2.2(1.5)$ & $1.6(1.0)$ & 0.00 & $2.5(1.9)$ & $1.9(1.2)$ & 0.00 \\
\hline $\mathrm{HDL}-\mathrm{C}(\mathrm{mmol} / \mathrm{L})^{\S}$ & $1.4(0.4)$ & $1.7(0.4)$ & 0.00 & $1.2(0.3)$ & $1.5(0.4)$ & 0.00 & $1.1(0.3)$ & $1.4(0.4)$ & 0.00 & $1.1(0.3)$ & $1.3(0.3)$ & 0.00 \\
\hline Total-C $(\mathrm{mmol} / \mathrm{L})^{\S}$ & $5.7(1.2)$ & $5.5(1.2)$ & 0.00 & $6.0(1.2)$ & $5.9(1.3)$ & 0.00 & $6.0(1.2)$ & $5.9(1.2)$ & 0.04 & $5.9(1.2)$ & $5.8(1.2)$ & 0.61 \\
\hline
\end{tabular}

Abbreviations: $M$ male, $F$ female, WC waist circumference, WHR waist-to-hip ratio, WHtR waist-to-height ratio, SBP systolic blood pressure, FPG fasting plasma glucose, TG triglyceride, HDL-C high-density lipoprotein cholesterol, Total-C total cholesterol. Data are means (standard deviations) or as noted.

*Difference between men and women.

${ }^{+}$The top quartile of WC, WHR or WHtR in women $(90 \mathrm{~cm}, 0.85$ or 0.56$)$ and in men $(99 \mathrm{~cm}, 0.97$ or 0.57$)$ was used as abdominal obesity group.

${ }^{*} 21555$ individuals with information on diabetes status, including 1285 with known diagnosis of diabetes and 20270 with available measurement of fasting plasma glucose and/or $75 \mathrm{~g} 2$-h oral glucose tolerance test (44.7\% women).

${ }^{\S} 573$ individuals with available measurement of SBP, 20759 for FPG, 36834 for TG, 41808 for HDL-C and 45353 for Total-C.

(Table 4). In addition, the gender difference among diabetic individuals diminished especially for non-obese ones.

The findings for BMI categories were not substantially altered when the analysis was repeated with additional adjusting for abdominal obesity (Additional file 1: Table S5). Multivariate adjustment for other CVD risk factors such as systolic blood pressure, fasting plasma glucose, triglyceride, high-density lipoprotein cholesterol or total cholesterol decreased the HRs in each obesity category for both men and women but the gender difference remained unchanged (Additional file 1: Table S6). A sensitivity analysis that excluded the first 5 years of follow-up did not alter the results (Additional file 1: Table S7).

\section{Discussion}

Men had a higher CVD mortality than women across all categories of anthropometric measures of obesity after adjusting for age, smoking status, leisure-time physical activity and cohort. The gender difference diminished somewhat in obese individuals especially among diabetic participants.

There is substantial evidence of a gender difference in cardiac autonomic modulation [2-5], lipid and glucose metabolism [6-9], sex hormones [4,10-14] and cytokines [15-19], that might explain part of the observed differences of CVD mortality between women and men. Besides, males tend to have more fat in the abdominal region, even among normal weight or non-obese men, which may be predominantly due to the accumulation of more visceral fat in males than females during the puberty [38].

In addition, sex hormones might play important roles in determining body fat mass and its distribution [11,14], exert multiple direct and indirect effects on insulin and glucose homeostasis or on cardiovascular physiology $[4,10,12,13]$. Specifically, estrogen increases fat deposition whereas testosterone inhibits fat deposition, and accordingly, men tend to have less overall body fat than women [14], however, the distribution differs between the sexes as discussed below. Women tend to accumulate more subcutaneous fat but less intra-abdominal fat than men probably due to the effects of estrogen by preventing androgen effects [39]. Intra-abdominal fat is believed to be the main pathogenic fat depot that has the clinical relevance to CVD [40], in particular being more metabolically active than adipose depots located in the hip, thigh or buttocks 
Table 3 Mortality rate per 10000 person-years and multivariate-adjusted hazard ratios for cardiovascular disease mortality in men and women by body mass index categories or sex-specific quartiles of anthropometric measures of abdominal obesity

\begin{tabular}{|c|c|c|c|c|c|c|c|c|c|c|}
\hline & \multicolumn{4}{|l|}{$\mathrm{BMI}, \mathrm{kg} / \mathrm{m}^{2}$} & \multicolumn{2}{|l|}{ WC, $\mathrm{cm}^{*}$} & \multicolumn{2}{|l|}{ WHR* } & \multicolumn{2}{|l|}{ WHtR ${ }^{*}$} \\
\hline & $<25.0$ & $25.0-29.9$ & $30.0-34.9$ & $\geq 35.0$ & $<90$ (F)/99 (M) & $\geq 90(\mathrm{~F}) / 99(\mathrm{M})$ & $<0.85$ (F)/0.97 (M) & $\geq 0.85$ (F)/0.97 (M) & $<0.56(\mathrm{~F}) / 0.57(\mathrm{M})$ & $\geq 0.56(\mathrm{~F}) / 0.57(\mathrm{M})$ \\
\hline \multicolumn{11}{|l|}{ No. of CVD deaths } \\
\hline Women & 90 & 107 & 81 & 61 & 173 & 166 & 195 & 144 & 159 & 180 \\
\hline Men & 241 & 459 & 198 & 47 & 506 & 439 & 555 & 390 & 480 & 465 \\
\hline \multicolumn{11}{|c|}{ Mortality rate (95\% Cl) } \\
\hline Women & $7(6-9)$ & $13(11-16)$ & $25(20-31)$ & $45(34-58)$ & $9(8-10)$ & $29(25-34)$ & $10(9-11)$ & $27(22-31)$ & $8(7-10)$ & $32(27-37)$ \\
\hline Men & $25(22-29)$ & $41(37-45)$ & $63(54-72)$ & $78(57-104)$ & $28(26-31)$ & $67(61-74)$ & $29(27-32)$ & $70(63-77)$ & $26(24-28)$ & $77(70-84)$ \\
\hline $\begin{array}{l}\text { Sex ratio in CVD } \\
\text { mortality rate (M/F) }\end{array}$ & 3.5 & 3.0 & 2.5 & 1.7 & 3.2 & 2.3 & 3.0 & 2.6 & 3.2 & 2.4 \\
\hline \multicolumn{11}{|c|}{ Hazard ratios $(95 \% \mathrm{Cl})^{\dagger}$} \\
\hline Women & 1.0 (Reference) & $1.0(0.8-1.3)$ & $1.5(1.1-2.0)$ & $2.8(2.1-3.9)$ & 1.0 (Reference) & $1.9(1.5-2.3)$ & 1.0 (Reference) & $1.6(1.3-2.0)$ & 1.0 (Reference) & $2.0(1.6-2.5)$ \\
\hline Men & $3.1(2.5-4.0)$ & $3.5(2.8-4.3)$ & $4.5(3.5-5.7)$ & $6.5(4.6-9.3)$ & $3.2(2.7-3.8)$ & $4.8(4.0-5.7)$ & $3.0(2.6-3.6)$ & $4.5(3.8-5.3)$ & $3.2(2.7-3.9)$ & $5.1(4.2-6.1)$ \\
\hline $\begin{array}{l}\text { Sex ratio in CVD } \\
\text { mortality risk (M/F) }\end{array}$ & $3.1(2.5-4.0)$ & $3.5(2.8-4.3)$ & $3.0(2.3-3.8)$ & $2.3(1.6-3.4)$ & $3.2(2.7-3.8)$ & $2.6(2.1-3.1)$ & $3.0(2.6-3.6)$ & $2.7(2.3-3.3)$ & $3.2(2.7-3.9)$ & $2.6(2.2-3.0)$ \\
\hline \multicolumn{11}{|c|}{ Hazard ratios $(95 \% \mathrm{Cl})^{\ddagger}$} \\
\hline Women & 1.0 (Reference) & $1.0(0.8-1.4)$ & $1.6(1.1-2.1)$ & $2.8(2.0-3.8)$ & 1.0 (Reference) & $1.9(1.6-2.4)$ & 1.0 (Reference) & $1.8(1.5-2.3)$ & 1.0 (Reference) & $2.1(1.7-2.6)$ \\
\hline Men & $2.8(2.2-3.6)$ & $3.1(2.5-3.9)$ & $3.8(2.9-4.9)$ & $5.4(3.8-7.7)$ & $2.9(2.4-3.4)$ & $4.1(3.4-5.0)$ & $2.7(2.3-3.2)$ & $4.2(3.5-5.1)$ & $3.0(2.5-3.6)$ & $4.4(3.6-5.3)$ \\
\hline $\begin{array}{l}\text { Sex ratio in CVD } \\
\text { mortality risk (M/F) }\end{array}$ & $2.8(2.2-3.6)$ & $3.0(2.4-3.7)$ & $2.4(1.8-3.2)$ & $2.0(1.3-2.9)$ & $2.9(2.4-3.4)$ & $2.1(1.8-2.6) \S$ & $2.7(2.3-3.2)$ & $2.3(1.9-2.8)$ & $3.0(2.5-3.6)$ & $2.1(1.8-2.5) \S$ \\
\hline
\end{tabular}

Abbreviations: $B M I$ body mass index, WC waist circumference, $W H R$ waist-to-hip ratio, $W H t R$ waist-to-height ratio, $F$ female, $M$ male, $C V D$ cardiovascular disease, $C l$ confidence intervals.

*The top quartile of WC, WHR or WHtR in women $(90 \mathrm{~cm}, 0.85$ or 0.56$)$ and in men $(99 \mathrm{~cm}, 0.97$ or 0.57$)$ was used as the abdominal obesity group.

${ }^{+}$Hazard ratios $(95 \% \mathrm{Cl})$ from the Cox proportional hazards model using attained age as time-scale.

${ }^{*}$ Hazard ratios $(95 \% \mathrm{Cl})$ from the Cox proportional hazards model adjusted for baseline smoking status, leisure-time physical activity, and cohort using attained age as time-scale.

${ }^{\mathrm{s}}$ Significance level $=0.05$ for interactions between obesity and gender. 
Table 4 Mortality rate per 10000 person-years and multivariate adjusted hazard ratios for cardiovascular disease mortality among non-diabetic and diabetic individuals by sex and body mass index categories or sex-specific quartiles of anthropometric measures of abdominal obesity

\begin{tabular}{|c|c|c|c|c|c|c|c|c|c|c|}
\hline & \multicolumn{4}{|l|}{ BMI, $\mathrm{kg} / \mathrm{m}^{2}$} & \multicolumn{2}{|l|}{$\mathrm{WC}, \mathrm{cm}^{*}$} & \multicolumn{2}{|l|}{$\mathrm{WHR}^{*}$} & \multicolumn{2}{|l|}{ WHtR ${ }^{*}$} \\
\hline & $<25.0$ & $25.0-29.9$ & $30.0-34.9$ & $\geq 35.0$ & $<90$ (F)/99 (M) & $\geq 90(\mathrm{~F}) / 99$ (M) & $<0.85$ (F)/0.97 (M) & $\geq 0.85(\mathrm{~F}) / 0.97(\mathrm{M})$ & $<0.56(\mathrm{~F}) / 0.57$ (M) & $\geq 0.56(\mathrm{~F}) / 0.57(\mathrm{M})$ \\
\hline \multicolumn{11}{|l|}{ Non-diabetic $(n=17056)$} \\
\hline \multicolumn{11}{|l|}{ Mortality rate $(95 \%$ Cl) } \\
\hline Women & $9(6-13)$ & $14(10-19)$ & $29(20-41)$ & $50(30-76)$ & $12(9-15)$ & $29(22-39)$ & $14(11-17)$ & $24(17-32)$ & $11(9-14)$ & $32(24-41)$ \\
\hline Men & $26(21-32)$ & $41(35-48)$ & $57(44-73)$ & $45(18-92)$ & $30(26-34)$ & $59(50-71)$ & $31(27-35)$ & $60(49-71)$ & $28(24-33)$ & $66(56-78)$ \\
\hline $\begin{array}{l}\text { Sex ratio in CVD mortality } \\
\text { rate (M/F) }\end{array}$ & 2.9 & 3.0 & 2.0 & 0.9 & 2.5 & 2.0 & 2.3 & 2.5 & 2.6 & 2.1 \\
\hline \multicolumn{11}{|l|}{ Hazard ratios $(95 \% \mathrm{Cl})^{\dagger}$} \\
\hline Women & 1.0 (Reference) & $1.0(0.7-1.6)$ & $1.8(1.1-3.0)$ & $3.3(1.9-5.8)$ & 1.0 (Reference) & $1.8(1.3-2.6)$ & 1.0 (Reference) & $1.5(1.0-2.2)$ & 1.0 (Reference) & $2.0(1.4-2.8)$ \\
\hline Men & $3.6(2.4-5.4)$ & $3.9(2.7-5.7)$ & $4.6(3.0-7.0)$ & $4.1(1.8-9.4)$ & $3.3(2.5-4.3)$ & $4.4(3.3-5.8)$ & $3.0(2.3-3.8)$ & $4.1(3.1-5.4)$ & $3.3(2.5-4.4)$ & $4.7(3.5-6.3)$ \\
\hline $\begin{array}{l}\text { Sex ratio in CVD mortality } \\
\text { risk (M/F) }\end{array}$ & $3.6(2.4-5.4)$ & $3.7(2.7-5.3)$ & $2.5(1.6-3.8)$ & $1.3(0.5-3.0)$ & $3.3(2.5-4.3)$ & $2.4(1.7-3.3)$ & $3.0(2.3-3.8)$ & $2.7(1.9-3.9)$ & $3.3(2.5-4.4)$ & $2.4(1.8-3.3)$ \\
\hline \multicolumn{11}{|l|}{ Hazard ratios $(95 \% \text { Cl) })^{\ddagger}$} \\
\hline Women & 1.0 (Reference) & $1.1(0.7-1.7)$ & $1.9(1.2-3.0)$ & $3.3(1.9-5.8)$ & 1.0 (Reference) & $1.9(1.4-2.8)$ & 1.0 (Reference) & $1.8(1.2-2.6)$ & 1.0 (Reference) & $2.0(1.4-2.9)$ \\
\hline Men & $3.2(2.1-4.8)$ & $3.4(2.3-4.9)$ & $3.9(2.5-6.0)$ & $3.8(1.7-8.6)$ & $2.9(2.2-3.8)$ & $3.8(2.8-5.1)$ & $2.6(2.0-3.3)$ & $4.1(3.1-5.6)$ & $2.9(2.2-3.9)$ & $4.0(2.9-5.4)$ \\
\hline $\begin{array}{l}\text { Sex ratio in CVD mortality } \\
\text { risk (M/F) }\end{array}$ & $3.2(2.1-4.8)$ & $3.1(2.2-4.4)$ & $2.1(1.4-3.2)$ & $1.2(0.5-2.7)$ & $2.9(2.2-3.8)$ & $2.0(1.4-2.7)$ & $2.6(2.0-3.3)$ & $2.3(1.6-3.3)$ & $2.9(2.2-3.9)$ & $2.0(1.4-2.7)$ \\
\hline \multicolumn{11}{|l|}{ Diabetic $(n=4499)$} \\
\hline \multicolumn{11}{|l|}{ Mortality rate (95\% Cl) } \\
\hline Women & $39(22-63)$ & 52 (36-74) & 57 (37-84) & $70(43-407)$ & $40(28-57)$ & 64 (49-83) & $37(26-51)$ & $73(55-94)$ & $35(23-51)$ & $66(51-83)$ \\
\hline Men & $54(36-77)$ & $118(95-144)$ & $138(103-182)$ & $146(80-245)$ & 80 (64-99) & $138(113-167)$ & $89(72-108)$ & $130(105-160)$ & $84(67-105)$ & $128(105-154)$ \\
\hline $\begin{array}{l}\text { Sex ratio in CVD mortality } \\
\text { rate (M/F) }\end{array}$ & 1.4 & 2.3 & 2.4 & 2.1 & 2.0 & 2.1 & 2.4 & 1.8 & 2.4 & 1.9 \\
\hline \multicolumn{11}{|l|}{ Hazard ratios $(95 \% \mathrm{Cl})^{\dagger}$} \\
\hline Women & 1.0 (Reference) & $1.0(0.6-1.9)$ & $1.0(0.5-1.8)$ & $1.3(0.7-2.5)$ & 1.0 (Reference) & $1.1(0.7-1.7)$ & 1.0 (Reference) & $1.3(0.8-1.9)$ & 1.0 (Reference) & $1.2(0.8-1.9)$ \\
\hline Men & $1.3(0.7-2.3)$ & $2.2(1.3-3.8)$ & $2.5(1.4-4.4)$ & $2.7(1.3-5.7)$ & $1.8(1.2-2.7)$ & $2.4(1.6-3.5)$ & $2.2(1.5-3.2)$ & $2.4(1.6-3.6)$ & $2.2(1.4-3.4)$ & $2.3(1.5-3.6)$ \\
\hline $\begin{array}{l}\text { Sex ratio in CVD mortality } \\
\text { risk (M/F) }\end{array}$ & $1.3(0.7-2.3)$ & $2.2(1.5-3.3)$ & $2.6(1.6-4.1)$ & $2.1(1.1-4.2)$ & $1.8(1.2-2.7)$ & $2.2(1.6-3.0)$ & $2.2(1.5-3.2)$ & $1.9(1.4-2.7)$ & $2.2(1.4-3.4)$ & $1.9(1.4-2.6)$ \\
\hline \multicolumn{11}{|l|}{ Hazard ratios $(95 \% \text { Cl) })^{\ddagger}$} \\
\hline Women & 1.0 (Reference) & $1.0(0.5-1.8)$ & $0.9(0.5-1.7)$ & $1.0(0.5-1.9)$ & 1.0 (Reference) & $1.2(0.8-1.8)$ & 1.0 (Reference) & $1.3(0.9-2.0)$ & 1.0 (Reference) & $1.3(0.8-2.1)$ \\
\hline Men & $1.3(0.7-2.4)$ & $1.9(1.1-3.2)$ & $1.9(1.1-3.5)$ & $1.6(0.8-3.4)$ & $1.9(1.2-2.9)$ & $2.1(1.4-3.2)$ & $2.1(1.4-3.2)$ & $2.3(1.5-3.5)$ & $2.2(1.4-3.6)$ & $2.3(1.4-3.6)$ \\
\hline Sex ratio in CVD mortality risk (MF) & $1.3(0.7-2.4)$ & $1.9(1.3-2.9)$ & $2.2(1.3-3.6)$ & $1.7(0.9-3.4)$ & $1.9(1.2-2.9)$ & $1.8(1.3-2.6)$ & $2.1(1.4-3.2)$ & $1.7(1.2-2.4)$ & $2.2(1.4-3.6)$ & $1.7(1.2-2.4)$ \\
\hline
\end{tabular}

Abbreviations: BMI body mass index, WC waist circumference, WHR waist-to-hip ratio, $W H t R$ waist-to-height ratio, $F$ female, $M$ male, $C l$ confidence intervals.

*The top quartile of WC, WHR or WHtR in women $(90 \mathrm{~cm}, 0.85$ or 0.56$)$ and in men $(99 \mathrm{~cm}, 0.97$ or 0.57$)$ was used as the obesity group.

${ }^{+}$Hazard ratios $(95 \% \mathrm{Cl})$ from the Cox proportional hazards model using attained age as time-scale. ${ }^{*}$ Hazard ratios $(95 \% \mathrm{Cl})$ from the Cox proportional hazards model adjusted for baseline smoking status, leisure-time physical activity, and cohort using attained age as time-scale. 
[41]. Clinical studies showed that there was higher intraabdominal fat accumulation in men than in women for a given level of BMI, WC or WHR [42-44]. In contrast, adult women tend to have a larger hip circumference than men. This is partly due to a difference in bone structure of pelvis, but also in subcutaneous fat mass, that through the metabolically protective physiology of gluteofemoral subcutaneous fat mass, perhaps by trapping excess fatty acids and preventing chronic exposure to elevated lipid levels, or through a beneficial adipokine profile (leptin and adiponectin) [45]. It remains unclear whether CVD risk differs by site of subcutaneous fat accumulation. In addition, estrogen might also play a role in the maintenance of glucose homeostasis and substrate metabolism [46]. Men had significantly higher fasting and significantly lower post-challenge insulin levels than women did $[8,47]$, which is not fully explained by differences in fasting and post-challenge glucose levels between sexes [47]. Additionally, adults have tended to show greater insulin resistance in men than in women $[7,9]$.

Adipose tissue is also a highly active metabolic and endocrine organ, which expresses and secretes a variety of bioactive factors including leptin, adiponectin, and other cytokines [19], which might contribute to the gender difference in CVD mortality. Women have higher circulating leptin levels and higher adiponectin levels than men [15-18]. Hyperleptinemia could be a sign of resistance to normal leptin signaling regulating food intake and satiety. This is believed to be a non-physiological state, which has been associated with an increased risk of diabetes, hypertension and CVD in men but not in women $[48,49]$. Additionally, hypoadiponectinemia has been found to be associated with an increased risk of both diabetes and CVD [50,51].

Obesity is associated with increased sympathetic activity and decreased vagal activity [52,53], hyperglycemia, insulin resistance [35,54], and is accompanied by chronic lowgrade inflammation $[19,55]$, hypertension and dyslipidemia [6,56,57], all of which might predispose to CVD. Abdominal obesity, in particular, is also associated with deficiency of estrogens or testosterone [58,59], although a causal link still needs to be established $[14,60]$. Deficiency of estrogens or testosterone has been consistently found to be associated with increased risk of CVD $[60,61]$. Increased leptin and decreased adiponectin levels were observed in obese individuals $[48,49,62]$, but the expression of these cytokines differed between subcutaneous and intra-abdominal fat depots $[17,63,64]$.

Interestingly, the gender difference in CVD mortality appears to somewhat diminish in obese individuals, although misclassification bias between obese and nonobese individuals might occur due to the gender difference of fat distribution, probably enhanced by disturbances of glucose metabolism. Causes of gender difference in CVD mortality with obesity are poorly understood. In our study, the attenuation of the gender difference in CVD mortality among obese individuals remained after adjustment of baseline age or other conventional CVD risk factors, or among non-diabetic individuals even when using other measures of abdominal obesity. The interactions of gender with anthropometric measures were, however, statistically significant only with WC and WHtR in the whole study population and not significant with any of the anthropometric measures in nondiabetic individuals. This suggests an effect modification by diabetes. Studies have indeed shown an attenuation of gender difference in CVD risk once women getting diabetes [24-27,29]. Still, there could be other potential unknown CVD risk factors clustering in obese women due to their older age that contributed to the increased CVD risk in obese women.

Since CVD previously has been considered a 'male disease' because of an earlier debut age on the average in men as compared with women, most epidemiological studies have been conducted primarily on men, leading to lesser prevention and treatment efforts in women [65]. Also, obese European women appear to be at greater risk of psychological dysfunction than obese men probably due to increased societal pressures on women to be thin in Europe [66]. In addition, obese women tend to have left ventricular concentric and eccentric hypertrophy, whereas obese men have predominantly concentric hypertrophy, the latter probably being more strongly related to cardiovascular mortality than eccentric hypertrophy, a finding noted recently [30].

Our study was based on several European populationbased or occupational studies, with sufficient power to investigate the association between obesity indicators and CVD mortality risk. Yet, limitations of the study exist. The study does not have data on changes in anthropometric measurements before baseline and during follow-up, which makes it impossible to exclude the possibility of 'reverse causation' [34], a consequence of underlying diseases before enrolment rather than a cause of deaths. This was examined by excluding the first five years of follow-up, and the results were little affected. Data are based on surveys of Caucasian Europeans, the results may not be applicable to other ethnic groups or races due to difference in percentage of body fat across ethnic groups [67]. Moreover, we do not have data on changes in anthropometric measurements after menopause. Rapid accumulation of abdominal fat after menopause has been suggested to reduce the gender difference in body fat distribution [11,68]. In addition, we do not have information on the use of hormone replacement therapy, which decreases weight gain and the accumulation of intra-abdominal fat in postmenopausal women 
[69]. Since this is a collaborative data analysis, certain lifestyle variables such as physical activity were recorded differently in different studies. Despite the efforts to "harmonize" variables and to adjust for the different studies in the data analysis, discrepancies exist. The discrepancies in study design and methodologies have been taken into account in our data analysis by fitting "study cohort" into the models as a co-variable, and by making a metaanalysis based on risk estimate of each single study. The effect of each study was also examined by removing each study from the pooled analysis. Exclusion of any study in the analysis had little overall influence on the main findings.

In summary, men had higher CVD mortality than women across all categories of anthropometric measures of obesity, but this gender difference in CVD mortality somewhat diminished in obese individuals, which warrants further investigation to understand the underlying mechanism.

\section{Appendix}

Studies and investigators in this collaborative study are:

Finland National FINRISK 1987, 1992 and 1997 Cohorts: J. Tuomilehto ${ }^{1,2,3}$, P. Jousilahti ${ }^{1}$, J. Lindström ${ }^{1}$, 1. Department of Chronic Disease Prevention, National Institute for Health and Welfare, Helsinki; 2. Center for Vascular Prevention, Danube University Krems, Krems, Austria; 3 King Abdulaziz University, Jeddah, Saudi Arabia.

National FINRISK 2002 Study: J. Tuomilehto ${ }^{1,2,3}, \mathrm{~T}$. Laatikainen $^{1,4,5}$, M. Peltonen ${ }^{1}$, J. Lindström ${ }^{1}$, 1. Department of Chronic Disease Prevention, National Institute for Health and Welfare, Helsinki; 2. Center for Vascular Prevention, Danube University Krems, Krems, Austria; 3 King Abdulaziz University, Jeddah, Saudi Arabia; 4. Institute of Public Health and Clinical Nutrition, University of Eastern Finland, Kuopio, Finland; 5. Hospital District of North Karelia, Joensuu, Finland.

Sweden Northern Sweden MONICA Survey: S. Söderberg ${ }^{1,2}$, M. Eliasson ${ }^{1}$, 1. Department of Public Health and Clinical Medicine, Umeå University, Umeå, Sweden; 2. Baker IDI Heart and Diabetes Institute, Melbourne, Australia.

Turkey Turkish Adult Risk Factor Study (TARFS): A Onat. Department of Cardiology, Cerrahpaşa Medical Faculty, Istanbul University, Istanbul, Turkey.

United Kingdom Whitehall II Study: M.G.Marmot ${ }^{1}$, A.G. Tabák ${ }^{1,2}$, M. Kivimäki ${ }^{1,3}$, E.J. Brunner ${ }^{1}$, D.R. Witte ${ }^{1,4}$, 1. Department of Epidemiology and Public Health, University College London, London, UK; 2. Semmelweis University Faculty of Medicine, $1^{\text {st }}$ Department of Medicine, Budapest, Hungary; 3. Finnish Institute of Occupational Health, Helsinki, Finland; 4. Steno Diabetes Center, Gentofte, Denmark.

\section{Additional file}

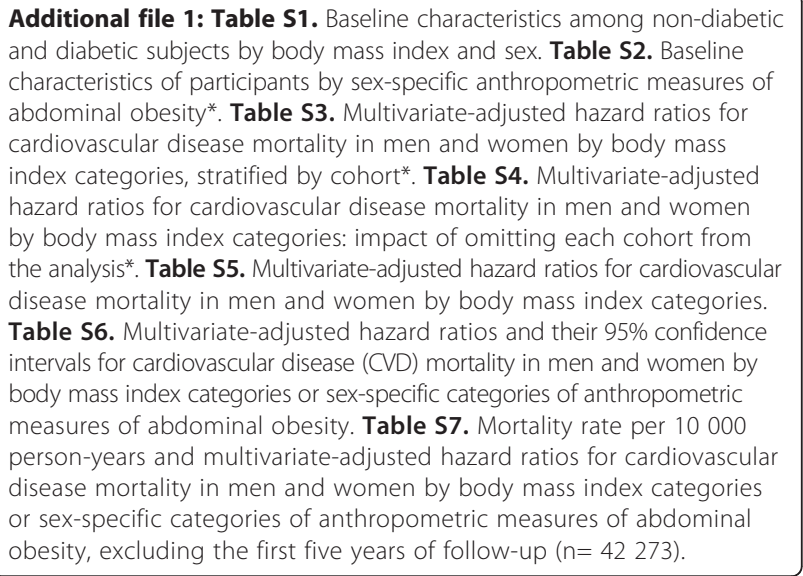

Competing interests

The authors declare that they have no competing interests.

\section{Authors' contributions}

XS initiated the study, prepared and analyzed the data, interpreted the results, drafted the manuscript, and contributed to the final version of the manuscript. QQ initiated the study, interpreted the results, and contributed to the final version of the manuscript. All coauthors contributed, revised and edited the manuscript. QQ is guarantor of this work and had full access to all the data in the study. All authors read and approved the final manuscript.

\section{Acknowledgements}

This study was supported by a grant from EC Health-2011-F2-279074-Project.

\section{Disclaimer}

Results and views of the presented study represent the authors' own and are not necessarily any official views of the Swedish Medical Products Agency where BZ is employed.

\section{Author details}

${ }^{1}$ Department of Public Health, Hjelt Institute, University of Helsinki, Helsinki, Finland. ${ }^{2}$ Department of Chronic Disease Prevention, National Institute for Health and Welfare, Helsinki, Finland. ${ }^{3}$ Department of Epidemiology and Public Health, University College London, London, UK. ${ }^{4} 1$ st Department of Medicine, Faculty of Medicine, Semmelweis University, Budapest, Hungary. ${ }^{5}$ Department of Public Health and Caring Sciences/Geriatrics, Uppsala University, Uppsala, Sweden. ${ }^{6}$ Medical Products Agency, Uppsala, Sweden. ${ }^{7}$ Department of Medicine, University College London, London, UK.

${ }^{8}$ Department of Public Health and Clinical Medicine, Umeå University, Umeå, Sweden. ${ }^{9}$ Baker IDI Heart and Diabetes Institute, Melbourne, Australia. ${ }^{10}$ Institute of Public Health and Clinical Nutrition, University of Eastern Finland, Kuopio, Finland. ${ }^{11}$ Hospital District of North Karelia, Joensuu, Finland. ${ }^{12}$ Department of Internal Medicine and Cardiovascular Research Institute Maastricht (CARIM), Maastricht University Medical Centre, Maastricht, The Netherlands. ${ }^{13}$ Unit for Cardiovascular Epidemiology, The Gertner Institute, Sheba Medical Center, Tel Hashomer, Israel. ${ }^{14}$ Division of Epidemiology and Prevention, School of Public Health, Sackler School of Medicine, Tel Aviv University, Tel Aviv, Israel. ${ }^{15}$ Department of Cardiology, Cerrahpaşa Medical Faculty, Istanbul, Turkey. ${ }^{16}$ Department of Clinical Sciences, Lund University, Malmö, Sweden. ${ }^{17}$ Center of Emergency Medicine, Skåne University Hospital, Malmö, Sweden. ${ }^{18}$ Istanbul University, Istanbul Medical Faculty, Istanbul, Turkey. ${ }^{19}$ Department of Clinical Medicine and Surgery, Federico II University, Naples, Italy. ${ }^{20}$ Center for Vascular Prevention, Danube University Krems, Krems, Austria. ${ }^{21}$ King Abdulaziz University, Jeddah, Saudi Arabia. ${ }^{22}$ Instituto de Investigacion Sanitaria del Hospital Universario LaPaz (IdiPAZ), Madrid, Spain. ${ }^{23}$ R\&D AstraZeneca AB, Mölndal, Sweden. 
Received: 14 July 2014 Accepted: 6 October 2014

Published online: 19 October 2014

\section{References}

1. World Health Organization: The Top 10 Causes of Death. Updated May 2014; Available at: http://who.int/mediacentre/factsheets/fs310/en/index.html, Accessed May 20, 2014.

2. Ramaekers $D$, Ector $H$, Aubert $A E$, Rubens $A$, Van de Werf F: Heart rate variability and heart rate in healthy volunteers. Is the female autonomic nervous system cardioprotective? Eur Heart J 1998, 19(9):1334-1341.

3. Dart AM, Du XJ, Kingwell BA: Gender, sex hormones and autonomic nervous control of the cardiovascular system. Cardiovasc Res 2002, 53(3):678-687.

4. Vaccarino V, Badimon L, Corti R, de Wit C, Dorobantu M, Hall A, Koller A, Marzilli M, Pries A, Bugiardini R, Working Group on Coronary Pathophysiology and Microcirculation: Ischaemic heart disease in women: are there sex differences in pathophysiology and risk factors? Position paper from the working group on coronary pathophysiology and microcirculation of the European Society of Cardiology. Cardiovasc Res 2011, 90(1):9-17.

5. Moodithaya S, Avadhany ST: Gender differences in age-related changes in cardiac autonomic nervous function. J Aging Res 2012, 2012:679345.

6. Freedman DS, Jacobsen SJ, Barboriak JJ, Sobocinski KA, Anderson AJ, Kissebah AH, Sasse EA, Gruchow HW: Body fat distribution and male/ female differences in lipids and lipoproteins. Circulation 1990, 81(5):1498-1506.

7. Donahue RP, Prineas RJ, DeCarlo DR, Bean JA, Skyler JS: The female 'insulin advantage' in a biracial cohort: results from the Miami Community Health Study. Int J Obes Relat Metab Disord 1996, 20(1):76-82.

8. Garaulet M, Perex-Llamas F, Fuente T, Zamora S, Tebar FJ: Anthropometric, computed tomography and fat cell data in an obese population: relationship with insulin, leptin, tumor necrosis factor-alpha, sex hormone-binding globulin and sex hormones. Eur J Endocrinol 2000, 143(5):657-666.

9. Magkos F, Wang X, Mittendorfer B: Metabolic actions of insulin in men and women. Nutrition 2010, 26(7-8):686-693.

10. Steinberg HO, Paradisi G, Cronin J, Crowde K, Hempfling A, Hook G, Baron AD: Type II diabetes abrogates sex differences in endothelial function in premenopausal women. Circulation 2000, 101(17):2040-2046.

11. Mayes JS, Watson GH: Direct effects of sex steroid hormones on adipose tissues and obesity. Obes Rev 2004, 5(4):197-216.

12. D'Eon TM, Souza SC, Aronovitz M, Obin MS, Fried SK, Greenberg AS: Estrogen regulation of adiposity and fuel partitioning. Evidence of genomic and non-genomic regulation of lipogenic and oxidative pathways. J Biol Chem 2005, 280(43):35983-35991.

13. Diabetes Prevention Program Research Group: Relationship of body size and shape to the development of diabetes in the diabetes prevention program. Obesity (Silver Spring) 2006, 14(11):2107-2117.

14. Singh R, Artaza JN, Taylor WE, Braga M, Yuan X, Gonzalez-Cadavid NF, Bhasin S: Testosterone inhibits adipogenic differentiation in 3 T3-L1 cells: nuclear translocation of androgen receptor complex with beta-catenin and T-cell factor 4 may bypass canonical Wnt signaling to downregulate adipogenic transcription factors. Endocrinology 2006, 147(1):141-154.

15. Saad MF, Damani S, Gingerich RL, Riad-Gabriel MG, Khan A, Boyadjian R, Jinagouda SD, el-Tawil K, Rude RK, Kamdar V: Sexual dimorphism in plasma leptin concentration. J Clin Endocrinol Metab 1997, 82(2):579-584.

16. Licinio J, Negrao AB, Mantzoros C, Kaklamani V, Wong ML, Bongiorno PB, Negro PP, Mulla A, Veldhuis JD, Cearnal L, Flier JS, Gold PW: Sex differences in circulating human leptin pulse amplitude: clinical implications. J Clin Endocrinol Metab 1998, 83(11):4140-4147.

17. Cnop M, Havel PJ, Utzschneider KM, Carr DB, Sinha MK, Boyko EJ, Retzlaff BM, Knopp RH, Brunzell JD, Kahn SE: Relationship of adiponectin to body fat distribution, insulin sensitivity and plasma lipoproteins: evidence for independent roles of age and sex. Diabetologia 2003, 46(4):459-469.

18. Steffes MW, Gross MD, Schreiner PJ, Yu X, Hilner JE, Gingerich R, Jacobs DR $\mathrm{Jr}$ : Serum adiponectin in young adults-interactions with central adiposity, circulating levels of glucose, and insulin resistance: the CARDIA study. Ann Epidemiol 2004, 14(7):492-498.

19. Kershaw EE, Flier JS: Adipose tissue as an endocrine organ. J Clin Endocrinol Metab 2004, 89(6):2548-2556.

20. Barnett SR, Morin RJ, Kiely DK, Gagnon M, Azhar G, Knight EL, Nelson JC, Lipsitz LA: Effects of age and gender on autonomic control of blood pressure dynamics. Hypertension 1999, 33(5):1195-1200.
21. Tremollieres FA, Pouilles JM, Cauneille C, Ribot C: Coronary heart disease risk factors and menopause: a study in 1684 French women. Atherosclerosis 1999, 142(2):415-423.

22. Peters HW, Westendorp IC, Hak AE, Grobbee DE, Stehouwer CD, Hofman A Witteman JC: Menopausal status and risk factors for cardiovascular disease. J Intern Med 1999, 246(6):521-528.

23. Couillard C, Bergeron J, Despres JP, Gagnon J, Rankinen T, Leon AS, Rao DC, Skinner JS, Wilmore JH, Bouchard C: Apolipoprotein Al- and Al:Allcontaining lipoproteins in white men and women of the HERITAGE Family study: Associations with metabolic risk profile variables. Metabolism 2003, 52(12):1530-1536.

24. Jousilahti P, Vartiainen E, Tuomilehto J, Puska P: Sex, age, cardiovascular risk factors, and coronary heart disease: a prospective follow-up study of 14786 middle-aged men and women in Finland. Circulation 1999, 99(9):1165-1172

25. Hu G, DECODE Study Group: Gender difference in all-cause and cardiovascular mortality related to hyperglycaemia and newly-diagnosed diabetes. Diabetologia 2003, 46(5):608-617.

26. Roche MM, Wang PP: Sex differences in all-cause and cardiovascular mortality, hospitalization for individuals with and without diabetes, and patients with diabetes diagnosed early and late. Diabetes Care 2013, 36(9):2582-2590.

27. Mascarenhas-Melo F, Marado D, Palavra F, Sereno J, Coelho A, Pinto R, Teixeira-Lemos E, Teixeira F, Reis F: Diabetes abrogates sex differences and aggravates cardiometabolic risk in postmenopausal women. Cardiovasc Diabetol 2013, 12:61-2840-12-61.

28. Kahn HS, Bullard KM, Barker LE, Imperatore G: Differences between adiposity indicators for predicting all-cause mortality in a representative sample of United States non-elderly adults. PLOS One 2012, 7(11):e50428.

29. Del Gobbo LC, Song Y, Poirier P, Dewailly E, Elin RJ, Egeland GM: Low serum magnesium concentrations are associated with a high prevalence of premature ventricular complexes in obese adults with type 2 diabetes. Cardiovasc Diabetol 2012, 11:23-2840-11-23.

30. Rider OJ, Lewandowski A, Nethononda R, Petersen SE, Francis JM, Pitcher A, Holloway CJ, Dass S, Banerjee R, Byrne JP, Leeson P, Neubauer S: Genderspecific differences in left ventricular remodelling in obesity: insights from cardiovascular magnetic resonance imaging. Eur Heart J 2013, 34(4):292-299.

31. Martins RA, Jones JG, Cumming SP, Silva MJ C e, Teixeira AM, Verissimo MT: Glycated hemoglobin and associated risk factors in older adults. Cardiovasc Diabetol 2012, 11:13-2840-11-13.

32. Shelton NJ: Regional risk factors for health inequalities in Scotland and England and the "Scottish effect". Soc Sci Med 2009, 69(5):761-767.

33. Han TS, Sattar N, Williams K, Gonzalez-Villalpando C, Lean ME, Haffner SM: Prospective study of $\mathrm{C}$-reactive protein in relation to the development of diabetes and metabolic syndrome in the Mexico City Diabetes Study. Diabetes Care 2002, 25(11):2016-2021.

34. Willett WC, Dietz WH, Colditz GA: Guidelines for healthy weight. N Engl J Med 1999, 341(6):427-434.

35. Kahn SE, Hull RL, Utzschneider KM: Mechanisms linking obesity to insulin resistance and type 2 diabetes. Nature 2006, 444(7121):840-846.

36. World Health Organization: Obesity: preventing and managing the global epidemic. Report of a WHO consultation. World Health Organ Tech Rep Ser 2000, 894(i-xii):1-253.

37. Alberti KG, Zimmet PZ: Definition, diagnosis and classification of diabetes mellitus and its complications. Part 1: diagnosis and classification of diabetes mellitus provisional report of a WHO consultation. Diabet Med 1998, 15(7):539-553.

38. Suliga E: Visceral adipose tissue in children and adolescents: a review. Nutr Res Rev 2009, 22(2):137-147.

39. Wajchenberg BL: Subcutaneous and visceral adipose tissue: their relation to the metabolic syndrome. Endocr Rev 2000, 21(6):697-738.

40. Klein S: The case of visceral fat: argument for the defense. J Clin Invest 2004, 113(11):1530-1532

41. Carey DG: Abdominal obesity. Curr Opin Lipidol 1998, 9(1):35-40.

42. Ross R, Shaw KD, Rissanen J, Martel Y, de Guise J, Avruch L: Sex differences in lean and adipose tissue distribution by magnetic resonance imaging: anthropometric relationships. Am J Clin Nutr 1994, 59(6):1277-1285.

43. Kuk JL, Lee S, Heymsfield SB, Ross R: Waist circumference and abdominal adipose tissue distribution: influence of age and sex. Am J Clin Nutr 2005, 81(6):1330-1334. 
44. Camhi SM, Bray GA, Bouchard C, Greenway FL, Johnson WD, Newton RL, Ravussin E, Ryan DH, Smith SR, Katzmarzyk PT: The relationship of waist circumference and BMI to visceral, subcutaneous, and total body fat: sex and race differences. Obesity (Silver Spring) 2011, 19(2):402-408.

45. Cameron AJ, Magliano DJ, Söderberg S: A systematic review of the impact of including both waist and hip circumference in risk models for cardiovascular diseases, diabetes and mortality. Obes Rev 2013, 14(1):86-94.

46. Louet JF, LeMay C, Mauvais-Jarvis F: Antidiabetic actions of estrogen: insight from human and genetic mouse models. Curr Atheroscler Rep 2004, 6(3):180-185.

47. Ferrara A, Barrett-Connor E, Wingard DL, Edelstein SL: Sex differences in insulin levels in older adults and the effect of body size, estrogen replacement therapy, and glucose tolerance status. The Rancho Bernardo Study, 1984-1987. Diabetes Care 1995, 18(2):220-225.

48. Söderberg S, Stegmayr B, Stenlund H, Sjöström LG, Agren A, Johansson L, Weinehall L, Olsson T: Leptin, but not adiponectin, predicts stroke in males. J Intern Med 2004, 256(2):128-136.

49. Lilja M, Rolandsson $\mathrm{O}$, Norberg $M$, Söderberg S: The impact of leptin and adiponectin on incident type 2 diabetes is modified by sex and insulin resistance. Metab Syndr Relat Disord 2012, 10(2):143-151.

50. Rabin KR, Kamari Y, Avni I, Grossman E, Sharabi Y: Adiponectin: linking the metabolic syndrome to its cardiovascular consequences. Expert Rev Cardiovasc Ther 2005, 3(3):465-471.

51. Oh DK, Ciaraldi T, Henry RR: Adiponectin in health and disease. Diabetes Obes Metab 2007, 9(3):282-289.

52. Arone $\amalg$, Mackintosh R, Rosenbaum M, Leibel RL, Hirsch J: Autonomic nervous system activity in weight gain and weight loss. Am J Physiol 1995, 269(1 Pt 2):R222-R225.

53. Karason K, Molgaard H, Wikstrand J, Sjostrom L: Heart rate variability in obesity and the effect of weight loss. Am J Cardiol 1999, 83(8):1242-1247.

54. Flier JS: Obesity wars: molecular progress confronts an expanding epidemic. Cell 2004, 116(2):337-350.

55. Onat A, Can G: Enhanced proinflammatory state and autoimmune activation: a breakthrough to understanding chronic diseases. Curr Pharm Des 2014, 20(4):575-584

56. Despres JP, Moorjani S, Lupien PJ, Tremblay A, Nadeau A, Bouchard C: Regional distribution of body fat, plasma lipoproteins, and cardiovascular disease. Arteriosclerosis 1990, 10(4):497-511.

57. Grundy SM, Brewer HB Jr, Cleeman JI, Smith SC Jr, Lenfant C, National Heart, Lung, and Blood Institute, American Heart Association: Definition of metabolic syndrome: report of the National Heart, Lung, and Blood Institute/American Heart Association conference on scientific issues related to definition. Arterioscler Thromb Vasc Biol 2004, 24(2):e13-e18.

58. Tchernof A, Poehlman ET, Despres JP: Body fat distribution, the menopause transition, and hormone replacement therapy. Diabetes Metab 2000, 26(1):12-20.

59. Stanworth RD, Jones TH: Testosterone in obesity, metabolic syndrome and type 2 diabetes. Front Horm Res 2009, 37:74-90.

60. Jones TH: Testosterone deficiency: a risk factor for cardiovascular disease? Trends Endocrinol Metab 2010, 8(21(8)):496-503.

61. Bulow B, Hagmar L, Eskilsson J, Erfurth EM: Hypopituitary females have a high incidence of cardiovascular morbidity and an increased prevalence of cardiovascular risk factors. J Clin Endocrinol Metab 2000, 85(2):574-584.

62. Havel PJ: Update on adipocyte hormones: regulation of energy balance and carbohydrate/lipid metabolism. Diabetes 2004, 53(Suppl 1):S143-S151.

63. Montague CT, Prins JB, Sanders L, Digby JE, O'Rahilly S: Depot- and sexspecific differences in human leptin mRNA expression: implications for the control of regional fat distribution. Diabetes 1997, 46(3):342-347.

64. Westerbacka J, Cornér A, Tiikkainen M, Tamminen M, Vehkavaara S, Häkkinen AM, Fredriksson J, Yki-Järvinen $\mathrm{H}$ : Women and men have similar amounts of liver and intra-abdominal fat, despite more subcutaneous fat in women: implications for sex differences in markers of cardiovascular risk. Diabetologia 2004, 47(8):1360-1369.

65. Stramba-Badiale M, Fox KM, Priori SG, Collins P, Daly C, Graham I, Jonsson B, Schenck-Gustafsson K, Tendera M: Cardiovascular diseases in women: a statement from the policy conference of the European Society of Cardiology. Eur Heart J 2006, 27(8):994-1005.

66. Carpenter KM, Hasin DS, Allison DB, Faith MS: Relationships between obesity and DSM-IV major depressive disorder, suicide ideation, and suicide attempts: results from a general population study. Am J Public Health 2000, 90(2):251-257

67. Expert WHO: Consultation. Appropriate body-mass index for Asian populations and its implications for policy and intervention strategies. Lancet 2004, 363(9403):157-163.

68. Kotani K, Tokunaga K, Fujioka S, Kobatake T, Keno Y, Yoshida S, Shimomura I, Tarui S, Matsuzawa Y: Sexual dimorphism of age-related changes in whole-body fat distribution in the obese. Int J Obes Relat Metab Disord 1994, 18(4):207-202

69. Sites CK, Brochu M, Tchernof A, Poehlman ET: Relationship between hormone replacement therapy use with body fat distribution and insulin sensitivity in obese postmenopausal women. Metabolism 2001, 50(7):835-840.

doi:10.1186/s12933-014-0144-5

Cite this article as: Song et al:: Obesity attenuates gender differences in cardiovascular mortality. Cardiovascular Diabetology 2014 13:144.

\section{Submit your next manuscript to BioMed Central and take full advantage of:}

- Convenient online submission

- Thorough peer review

- No space constraints or color figure charges

- Immediate publication on acceptance

- Inclusion in PubMed, CAS, Scopus and Google Scholar

- Research which is freely available for redistribution 